\title{
A Study on the Perception of Walkability in Tourist Attraction Places in Qatar using Text Mining Techniques
}

\author{
Jiin BAEK, Qatar University, Qatar \\ Mohd Faris KHAMIDI, Qatar University, Qatar
}

\begin{abstract}
Walking is an important part of the tourist experience and comfort travel. There is increasing attention to encourage tourists to walk as a mode of sustainable transportation. Emergence of new and diverse forms of data has expand the field of research via text mining analysis. This is an alternative for common research methodology as a good analysis tool to reflect pedestrians' opinions in spatial design and urban planning. In this regard, the novelty of this paper is to investigate the relationship between walkability and successful tourism in Doha, Qatar by utilizing text mining analysis on a readily available datasets, i.e. the customer generated contents from TripAdvisor. The collected data for tourist attractive places in Doha, Qatar shows higher frequency (connection) of words that reflect the characteristics of each research location and its respective relationship with public transportation (Doha Metro) to support the walkable environment. The findings have determined some users-friendly walking environment especially for research locations like The Pearl, Souq Waqif and Museum of Islamic Arts. On the other hand, it is indicated that the rate of Metro use is still low compared to the city's population and this will take some time for Doha Metro to be used as main mode of transportation among the tourists. The outcome of this study will enable to propose some guidelines to enhance the walking environment for tourists within the challenging weather condition like hot and arid climate of Qatar.
\end{abstract}

\section{Keywords}

Walkability, Tourism, Text Mining Analysis, Sustainable Transportation, Doha Metro

\section{Introduction}

Walkable neighborhood is currently a key factor of sustainable community (Speck, 2013) to encourage health, economic, and social development instead of car-based urbanism. As Talen \& Koschinsky (2013) argued that a search on Google Scholar for "walkable neighborhood" returns over 500 entries, $96 \%$ of which were published since 2000, representing many scholars are interested in the better walkable environment. In recent years, studies on how to make a better walkable environment has gained interests from professionals, academics and researchers.

Sustainable urban quality of the built environment are often considered the significant measure of walking and walkability as attractive for locals, visitors and tourists (Talen, 2002). Pedestrian-friendly street design with walkable environment and improvement of walk community have been represented as improving biological public health, reducing in traffic congestion and air pollution, ecological foot print. (Forsyth \& Southworth, 2008)

Walking is also a significant factors for tourist and outdoor recreational activity and element of sustainable mobility, with walking trails and pilgrimage routes significant attractions in their own right (Timothy and Boyd, 2015). Although little attention has been given to the concept of walkability from a tourist 
perspective, there is increasing attention to encouraging tourists to walk as a mode of sustainable transportation. (Hall et al., 2017)

Walking is an important part of the tourist experience and comfort travel. Public transportation is the main mean of transportation (utilities) for tourist in new place. Public transportation plays an important role in tourism development at a destination; especially in urban areas' tourists experience with public transportation, service may influence their satisfaction with a destination (Thompson \& Schofield, 2007).

The subject of walkability has been analyzed with various method approaches such as measuring walkability with google street view, walk score or auditing tool, connection to the other transportation mode, GIS analysis, and so on. With developments in ICT and the massive growth in social media usage, however, new and diverse types of data continues to increase and massive amounts of data can be processed in real time in these days. Text mining, among various big data analysis techniques, is emerging in diverse fields as a way to supplement the limitations of existing sociological methods such as quantitative and objective data that can assist qualitative opinions (Won and Kim, 2014), extracting valuable information from main keywords, relationship between keywords.

This research investigates the relationship between walkability and successful tourism in Doha, Qatar by analyzing based on customer generated contents from TripAdvisor. While typically assumed that the Qatar's hot climates constrain people's walking patterns, it is necessary to examine the value of tourist's perception/opinion of walking and walkable environment in famous tourist places in Doha. TripAdvisor data, believed to be the most influential sites to inform travel choices and tourist behavior (Gursoy et al. 2017), as indicators of successful tourism, is examined to select high ranked attractive places in Doha as per the number of visitors and rankings

For the purpose of this research, main research questions are summarized into three queries:

- What are Tourists opinion about walkability between different leading tourism places and public transportation in Doha, Qatar?

- How can text mining analysis represents/reflects the tourist's opinion of built environment in study places?

- How mapping analysis with field observation technique can be applied to study the physical built environment in the selected places?

By imposing a layer of real tourist perception or opinion to the place, the research aims to improve specificity of the outcome on top of extracting overall sentiment about the place. The novelty of our paper in this sense is that we apply a relational approach by conducting a network analysis methodology on a readily available data source: customer generated content (CGC) from TripAdvisor while carrying out a field observation for better understanding of physical built environments in the site. It would be a helpful study for Qatar, which is set to host the 2022 FIFA World Cup, to enhance their tourism policy and eventually to provide better experience for visitors, by analyzing Qatar Doha's walking environments and its walkability in terms of tourist destination connectivity.

\section{Background Research}

\subsection{Walkability and Tourism}

Given the growing interest in the relationship between tourism and urban design and a desire to make tourism more sustainable and destinations more attractive, there has been a growing interest in the relationships between tourism and walkability (Ram and Hall, 2018). Many tourists believe that the best way to experience a city is to walk it (Thompson, 2004). 
Walkability can be broadly defined as the extent to which built environment usually enables walking (Kelly et al., 2011). A development case of TOD (Transit Oriented Development) is an example of how walkability affects the physical built environment considering public transportation's direct impact on walkability. As Forsyth (2015) noted walkability is used to refer to three related though different concepts: environmental features or means of making walkable environments; outcomes potentially fostered by such environments; and as a proxy for better urban design.

The proper walkable distance for pedestrian has been studied and analyzed through various stages. $5 \mathrm{~min}$ walking distance, also known as people are willing to walk before opting drive, is generally accepted and is represented by a radius $1 / 4$ mile or about $400 \mathrm{~m}$ based on average walking speed for a five-minute walk. According to Lo (2009), comparing different cities, a number of commonalities in walkability's criteria can be seen in the following: Presence and continuity of sidewalks and pedestrian routes; Accessibility of facilities to people with different abilities; Directness of pedestrian paths and connectivity of the street network; Connections to frequent transit services; Ease and safety of crossings; Visual interest; and Perceived or actual security. Quantitative measures tend to miss qualitative factors such as sense of enclosure, liveliness, safety, litter (Owen, 1993). Therefore site observation and mapping analysis, as auditing tool with field survey, is indispensable to understand neighborhood's quality of life and to evaluate the effects of street-scale characteristics, traffic volume and speed, presence of multiple destinations, or indicators of social or physical disorder.

Even though, increasing attention has been given to walkable environment of tourist as a measure of sustainable transportation, there is a very limited number of studies specifically examining walkability from a tourist perspective (Ram and Hall, 2018). Le-Klähn et al. (2015) reported that 60 percent of visitors engaged in walking as a means of active transportation either in conjunction with public transportation or separately. The built environment encouraging the walkability, therefore, may affect tourist's interest in walking a destination (Samarasekara et al., 2011), while walkability is potentially also an asset for tourist attractions and services, such as transportation hubs and accommodation (Ram et al., 2016).

\subsection{Tourism and Public Transportation}

There are extensive discussion about the use of public transportation (PT) associated with tourism since 2000 (Scott et al., 2012), encouraging the use of alternative modes such as non-motorized modes and public transportation (Dubois et al., 2011). Tourist preferences for trip mode differ from that of daily transportation (Malhado \& Rothfuss, 2013). A user-friendly PT network is necessary to motivate greater use. Additional critical aspects include efficiency, safety and service frequency.

There is a variety of public transportation like tram, metro, bus, taxi, and etc. Of which, the Metro is the most commonly used mode for tourists in many cities such as Paris, London, Seoul, Tokyo, and so on. Public Transportation, such as Metro, is more flexible means to accommodate a number of tourists and to provide more connectivity and accessibility to destinations. It is obvious transportation accessibility and connectivity affect tourist choice of recreational destinations (Xiao et al., 2012). In line with sustainability trend, public transportation is expected to take and play a significant role as a transportation mode in the tourism. (Gossling, 2010).

As tourism seeks to become more sustainable, more active travel modes are encouraged when visiting tourist attraction places (Hall et al., 2017). Public transportation acts an important role in tourism development at a destination in urban areas (Le-Klahn and Hall, 2015) and an excellent public transportation networks attracts tourist to use public transportation (Le-Klahn et al., 2014). A city with well-organized public transportation networks has a potential of being more attractive to tourists. 


\subsection{Text Mining Process}

According to the IBM report (2015), it is estimated that $80 \%$ of the world's data is mostly unstructured data like text. There is a wealth of information in the text we encounter every day, but in these days, millions of unstructured data, such as documents, email, social media, images, etc., are produced on daily basis, meaning a limit to processing vast amounts of text data with only cognitive ability. As Businesses sectors use structured data through rational databases and spreadsheets by identifying its pattern, with paradigm shift in data growth form mostly structured to mostly unstructured, it is necessary to gain insight efficiently from vast amount of unstructured data.

The latest sentiment analysis researches have produced relatively focused reviews and opinions with text mining, based on Customer Generated Contents (CGC) which are datasets of specific topic-oriented (Oh, 2015). This CGC approach offers unrestricted and unbiased opinions on topics (Liu, 2010). Therefore, by using CGC to extract and construct an overall sentiment from a vast number of feedbacks can support to predict the success of a future strategy. Implementation of text mining technique in tourism sector seems to provide the most credible correlation (Garcia, 2012; Akehurst, 2009) due to the fact of dealing with physical features of built and tangible environment, therefore, share a similar goal (Oh, 2015).

Preprocessing that organize data and word representation that transform preprocessed text into mathematical expressions are sequential tasks that must be performed to analyze text. Text can then be analyzed by applying various analysis methods; Logistic accounting analysis of machine learning, Support Vector Machine (SVM), and k-th nearbar (Knn) can be applied to classify documents by characteristics; we can find specific topics in the documents through the topic analysis; and you can extract the tone embedded in documents dealing with similar topics and extract a time series containing useful information if Sentiment Lexicon is in place. Jung (2010) said that the general process of text mining typically goes through four steps; Unstructured Information Collection - Information Processing - information Extraction - Information Analysis. This research follows the general procedures. Figure 1 below indicates the general process of text mining from the crawling data of Customer Generated Contents (CGC).
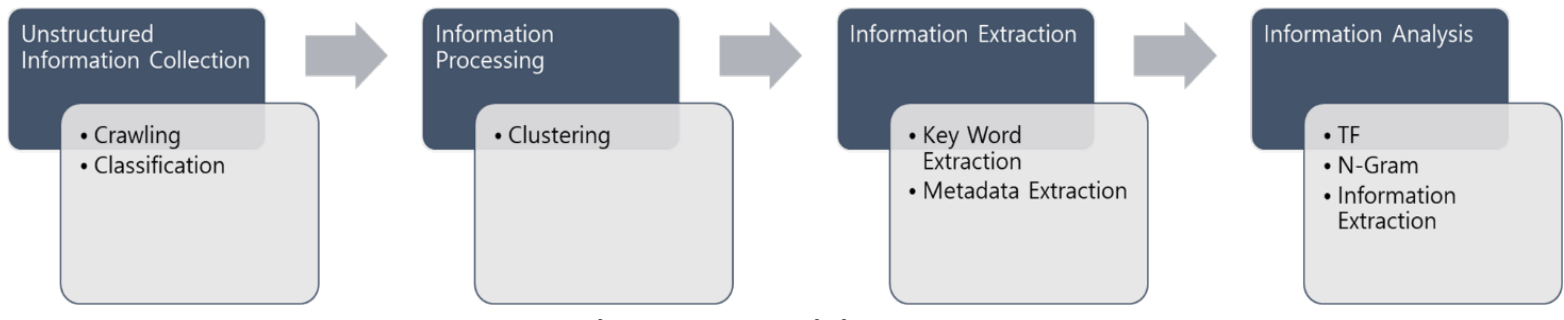

Figure 1. Text Mining Process

\section{Methodology}

Among various CGC platforms, to measure the impact of tourists' walkability and recognition, TripAdvisor CGC data is adopted to have the most efficient and effective dataset of reviews for this study in consideration the data's accessibility, unbiased, and informative rationale (Table 1). In TripAdvisor, every review combines a description of an experience (qualitative information) and a score representing the value ascribed to the experience (quantitative information). With all domestic and foreign tourists' reviews, moreover, we can see diverse spectrum of perspective on the place. 
Table 1. CGC Data from TripAdvisor

\begin{tabular}{|l|l|}
\hline \multicolumn{1}{|c|}{ Rationale } & \multicolumn{1}{c|}{ Data Qualities } \\
\hline $\begin{array}{l}\text { Accessibility } \\
\text { and Popularity }\end{array}$ & $\begin{array}{l}-463 \text { million website visitors per month } \\
\text { - More than } 867 \text { million reviews and opinions from } 49 \text { different countries in } 28 \\
\text { languages } \\
\text { - More than 145,000 global destinations listed and reviewed } \\
\text { *Sources from Tripadvisor.com }\end{array}$ \\
\hline Unbiased & $\begin{array}{l}\text { - Data/reviews are available at free without any award for this study } \\
\text { - Already randomly existing data, not specially generated information for this } \\
\text { study. }\end{array}$ \\
\hline Informative & $\begin{array}{l}\text { - Readily available information of features, perception, behaviors about a } \\
\text { selected place }\end{array}$ \\
\hline
\end{tabular}

The diagram in Figure 2 summarizes the research methodology of this study.

\begin{tabular}{|c|c|}
\hline \multicolumn{2}{|c|}{ Walkability sustainable city } \\
\hline & \\
\hline \multicolumn{2}{|c|}{ Walkability of tourist } \\
\hline \multicolumn{2}{|l|}{$\downarrow$} \\
\hline Mapping Analysis & Text Mining Analysis \\
\hline $\begin{array}{l}\text { - Streetscape Image } \\
\text { - Google map analysis of each } \\
\text { selected site }\end{array}$ & $\begin{array}{l}\text { - } \text { Data Collection } \\
\text { - Key word extraction } \\
\text { - } \text { Data Refining } \\
\text { - } \text { Key word, TF-IDF, N-Gram }\end{array}$ \\
\hline \multicolumn{2}{|r|}{$\downarrow$} \\
\hline Mapping Analysis result & Text Mining Result \\
\hline $\begin{array}{l}\text { - Walkable distance } \\
\text { - Streetscape quality }\end{array}$ & $\begin{array}{l}\text { - Key word Frequency } \\
\text { - Visualization and interpretation }\end{array}$ \\
\hline \multicolumn{2}{|l|}{$\downarrow$} \\
\hline \multicolumn{2}{|c|}{ Conclusion } \\
\hline
\end{tabular}

Figure 2. Flow Chart of Research

\subsection{Site Selection - Tourism in Doha}

Following Annual tourism performance report, 2019, Qatar welcomed 2.136 million visitors in 2019, representing an increase of $17 \%$ compared to the same period in 2018 . Doha is located on the central-east portion of Qatar, bordered by the Persian Gulf on its coast. Qatar has become increasingly popular around the world over the last two decades, owing in large part to three phenomena: the abundance of oil; airline business; and iconic cultural complexes such as the Museum of Islamic Art (MIA), National Museum of Qatar(NMQ) and the Islamic Cultural Center. Innovative urban regeneration schemes, in addition, such as Souq Waqif and Msheireb Downtown Doha, are providing a strong cultural heritage focus for an attractive tourism in Doha.

Based on our research purpose, leading tourism places in Doha are selected; Pearl, Katara, Souq Waqif, Museum of Islamic Art (MIA), and National Museum of Qatar (NMQ) (Figure 3). These places are representative tourist destinations in Qatar and selected as Travelers' Choice Awards by TripAdvisor. 
Reviews on the five attractions along with its physical built environment condition are considered in text mining analysis. Additionally, to enhance the understanding of the five-site physical built environment, field observation measures were applied.

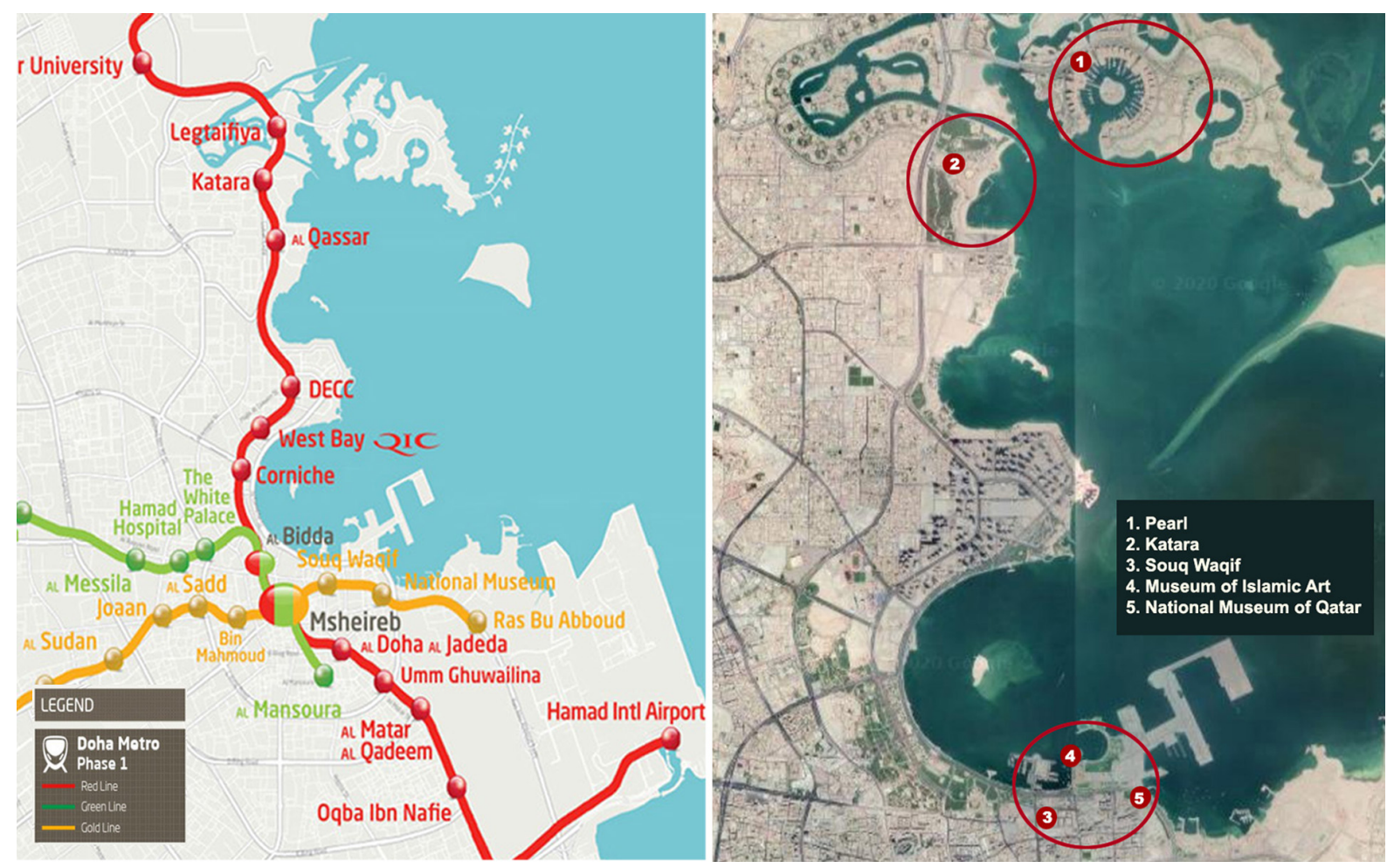

Figure 3. Doha Metro Map and Five Selected Tourist Attractions

While the main public transportation system was bus and taxi including Uber, the launching of Doha Metro means step up to the active pedestrian movement increasing accessibility. Doha Metro, as shown in Figure 3 above, is a rapid transit system in Doha started its operation in May 2019. It consists of the three lines (Red Line, Green Line, and Gold Line), providing approximately $76 \mathrm{~km}$ with 37 station. From the central interchange station at Msheireb, the Red line connects from North (Lusail) to South (Wakra) of Doha, the Green line called as the educational line, runs from the west of Doha passing through the educational city, and the Gold lines passes stations placed in major historical and cultural areas like Souq Waqif and NMQ (Al-Harami, 2020). It provides free Metrolink service, a feeder bus network providing first and last mile connectivity to Qatar Rail customers within 2 to 5 kilometer radius of Doha metro service, to enhance more walkable city promoting the usage of public transportations. This system will provide lots of benefit for Doha's tourism business especially with hosting of 2022-FIFA World Cup.

\subsection{Field Observation}

Walkability is measured in between metro stations (Origin) and tourism places (Destinations) in terms of proximity, place's surroundings, and walkable built environments around. According to Moudon and Lee (2003), well-maintained walking surfaces, destinations, and public transit were correlated with walking for transport or recreation, therefore, microscale element is necessary to understand tourist's movement. Observations of visiting five sites in a week were carried out on sunny days during temperatures of $35^{\circ} \mathrm{C}$ between 4:30pm and 5:30pm in May. Mainly outdoor pedestrian environment features were observed. Streetscape feature in auditing tool such as distance, pavement, shade, streetscape feature, and landscape are investigated by photos and site observation. In many respects, there is a big gap to use full auditing 
tool in Doha, Qatar, therefore, selected auditing tool has been measured in our sites related to the connectivity, comfort, wayfinding, and shade.

\subsection{TripAdvisor Reviews Text Mining}

Text mining allows you to choose when, what, and samples you need to study, and above all, the number of samples is larger than the survey, so that the errors in the results are relatively small and information can be obtained quickly (Jung, 2010). The relationship between derived keywords can be identified to figure out the causes and factors that influence the keywords.

The field of Sentiment Analysis, known as Opinion Mining, is more popularly adopted in the field of marketing and business (Liu, 2010). There is no previous research found applying sentiment analysis for evaluation of walkability in a tourist attractive area. Given literature review to analyze the data analysis, we will follow the four steps; Unstructured Information Collection - Information Processing - information Extraction - Information Analysis (Jung, 2010).

\subsubsection{Selection of Datasets and Research Locations}

Using the big data program for text mining, data from May 2019 when Metro began operation to the present day, the results of a text mining analysis for each five attraction place along with its physical built environment condition were compared and analyzed from the TripAdvisor review left by travelers.

This paper analyzes 'walk' and its related information and public transportation 'Doha Metro' from dataset collected from TripAdvisor. Text mining can identify how pedestrian's perception of walk and transit has affected since new public transportation (Metro) began operation. Keywords from each of the five sites were derived by utilizing the big data solution program, TEXTOM, which consists of programs such as $C+, R$ and Python.

\subsubsection{Data Collection and Data Processing}

First step is to collect and analyze data from the TripAdvisor reviews. With web crawler program, customer generated articles from TripAdvisor for the selected places are retrieved and stored in the CGC Database. At the stage of data collection (Table 2), the main key word is selected as "walk". The natural langue of data collected is English. The data is collected randomly, excluding non-text data such as pictures and photographs in $1^{\text {st }}$ stage and math symbols, programming languages, and chemical formulas in $2^{\text {nd }}$ stage. The CGC Database is checked and reviewed to verify every opinion is based on personal travel experiences to avoid noise in the dataset.

Table 2. Dataset Collection from TripAdvisor

\begin{tabular}{|l|l|c|}
\hline \multicolumn{1}{|c|}{ Tourist Place } & Data Period & User Reviews from TripAdvisor \\
\hline Pearl & May-2019-Jun 2020 & 165 \\
\hline Katara & May-2019-Apr 2020 & 153 \\
\hline Souq Waqif & May-2019-July 2020 & 651 \\
\hline Museum of Islamic Art & May-2019-July 2020 & 347 \\
\hline Qatar Museum & May-2019-Jun 2020 & 265 \\
\hline Metro & May-2019-May 2020 & 146 \\
\hline
\end{tabular}

Total number of user reviews (Table 2) are crawled and archived. Each data entry is assigned with unique ID number so that the unique review can be traced back at the evaluation stage. 


\subsubsection{Extracting and Analyzing Value from Datasets; Extracted Keyword TF-IDF \& N-Gram}

TF-IDF (Term Frequency-Inverse Document Frequency) is a method of weighting a word according to frequency and relative importance. Through the refining process of the collected data, preposition, postposition, and connection were removed through the refining process. For example, the investigation of is, was, be, etc. is high in frequency, so removal through the refining process is necessary. An analysis of spelling errors, adjectives of similar meaning, through deletion or merging process, is made into finally collected text. Several refining processes have been carried out in each tourist place to derive a keyword that fits the research topic of 'Walk' and other relevant keywords.

Word Cloud is created to visualize important contents of the related information. Through the refining process, in addition, the importance hierarchy of the extracted word in the data can be known through a Term Frequency (TF) and Network Graph (N-Gram). A TF is a word frequency value that indicates how open a particular word appears in a document within a certain range meaning the high frequency of a particular word, the more important within the document (Jung, 2010). N-Gram is a language model that is typically used to process text data and is used to predict probabilistically the next word by expressing a chain of ' $\mathrm{N}$ ' words, using N-Gram as the basis for emotional analysis in various studies (Kim et al., 2019). Keywords have limitations in identifying regional characteristics with TF alone, so check N-Gram is checked for analyzing the results.

\section{Results}

\subsection{Field Observations}

Shown in Table 3 and Figure 4, for Katara, Souk Waqif, NMQ, there is well connected underground connection from Metro Station to each tourist attraction area (Destination). The distance between Metro Station and tourist attraction is mostly within $200 \mathrm{~m}$ boundary which is an appropriate distance within 1/4 mile recommended by the sustainable urban design (according to New Urbanism). With the clean and pleasant air conditioned pathway and clear signage system, in addition, it is an optimal environmental for pedestrian to move easily, meaning good accessibility and connectivity. In the case of Pearl and MIA, the two places do not seem to have initially considered the connectivity and accessibility by Metro as it is far from the distance that pedestrians can easily access. As it appears in the text mining analysis, tourists who visit the Pearl often use the Doha travel agency bus. The MIA, even though, is not far from Souk Waqif, there is low pedestrian connectivity between the two places and lack of shade or natural landscape where it is necessary.

Table 3. Streetscape Characteristics in Each Tourist Attractive Places

\begin{tabular}{|l|l|l|l|l|l|}
\hline Location & \multicolumn{1}{|c|}{$\begin{array}{c}\text { Distance } \\
\text { from Metro }\end{array}$} & $\begin{array}{c}\text { Signage } \\
\text { for Metro }\end{array}$ & $\begin{array}{c}\text { Pavement } \\
\text { /Pedestrian Crossing }\end{array}$ & Side Walk Shading & $\begin{array}{l}\text { Natural Landscape/ } \\
\text { Art Sculpture }\end{array}$ \\
\hline Pearl & N/A & $\begin{array}{l}\text { Pedestrian-friendly } \\
\text { pavement/ No car }\end{array}$ & $\begin{array}{l}\text { Shade by buildings. } \\
\text { No shade in } \\
\text { Promenade. }\end{array}$ & $\begin{array}{l}\text { Water Fountain, } \\
\text { Park. }\end{array}$ \\
\hline Katara & $\begin{array}{l}110 \mathrm{~m} \mathrm{/} \mathrm{Direct} \\
\text { connection through } \\
\text { underground } \\
\text { passage from Metro }\end{array}$ & Signage & $\begin{array}{l}\text { Pedestrian-friendly } \\
\text { pavement/Controlled } \\
\text { car-speed, Golf cart } \\
\text { pick up service for } \\
\text { visitors }\end{array}$ & $\begin{array}{l}\text { Shade created by } \\
\text { buildings (Sikka- } \\
\text { narrow corridor) }\end{array}$ & $\begin{array}{l}\text { Natural Landscape } \\
\text { (Park), Art } \\
\text { Sculptures, Water } \\
\text { Fountain, Retails }\end{array}$ \\
\hline $\begin{array}{l}\text { Souk } \\
\text { Waqif }\end{array}$ & $\begin{array}{l}\text { 200m(Exit main } \\
\text { station)/ Direct } \\
\text { connection through }\end{array}$ & Signage & $\begin{array}{l}\text { Dedicated Pedestrian } \\
\text { walkway/ No Car }\end{array}$ & $\begin{array}{l}\text { Shade created by } \\
\text { buildings (Sikka- } \\
\text { narrow corridor) }\end{array}$ & $\begin{array}{l}\text { Art Sculptures, } \\
\text { Water Fountain, } \\
\text { Retails }\end{array}$ \\
\hline
\end{tabular}


Baek, J.; Khamidi, M.F.

A Study on the Perception of Walkability in Tourist Attraction Places in Qatar using Text Mining Techniques

\begin{tabular}{|c|c|c|c|c|c|}
\hline & $\begin{array}{l}\text { underground } \\
\text { passage from Metro }\end{array}$ & & & & \\
\hline $\begin{array}{l}\text { Museum } \\
\text { of Islamic } \\
\text { Art }\end{array}$ & N/A & $\mathrm{N} / \mathrm{A}$ & $\begin{array}{l}\text { Pedestrian walkway/ } \\
\text { No Car. } \\
\text { Golf cart pick up } \\
\text { service for visitors }\end{array}$ & None & $\begin{array}{l}\text { Water Feature in } \\
\text { Main Entrance }\end{array}$ \\
\hline $\begin{array}{l}\text { National } \\
\text { Museum } \\
\text { of Qatar }\end{array}$ & $200 m$ & $\begin{array}{l}\text { Signage } \\
\text { (Under } \\
\text { Construction) }\end{array}$ & $\begin{array}{l}\text { Golf cart pick up } \\
\text { service for visitors }\end{array}$ & None & Desert Landscape \\
\hline
\end{tabular}

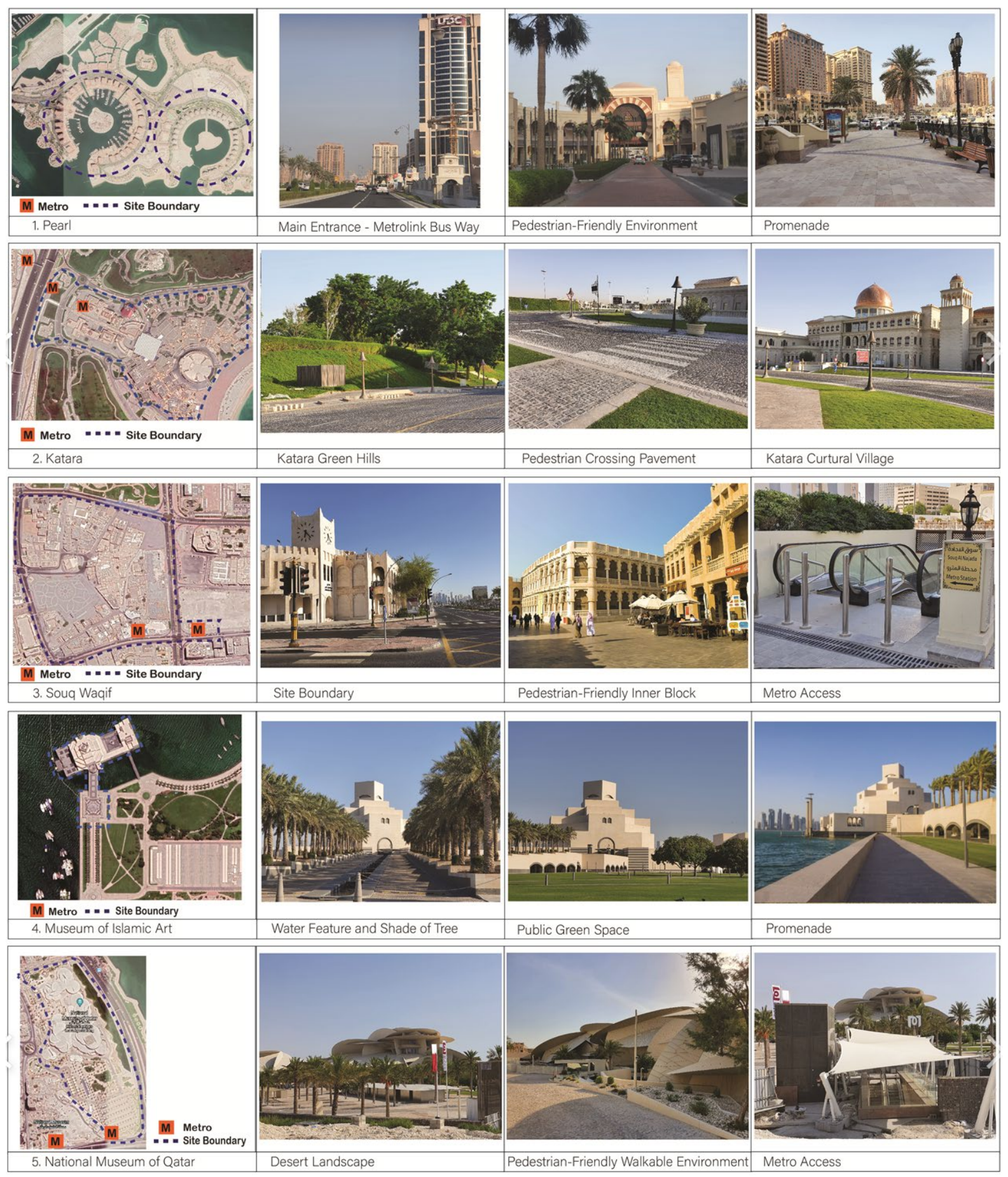

Figure 4. Streetscape Photo for Each Site 


\subsection{Text Mining Result}

Using text mining techniques, Customer Generated Contents (CGC) from TripAdvisor for the selected five tourist places analyzed. Since there was a separate review section for Metro in TripAdvisor, Metro section was also analyzed to find out people's perception on the newly introduced public transportation. The total of 1,580 reviews were analyzed. As shown in Table 4, there is a difference in the number of reviews according to each location. Two refining operations were carried out; 1 . Data analyzing of the original review itself per each place; 2. Extracting data from the each place based on the keyword "walk". When analyzing the entire review of the TripAdvisor itself, the number of TF data is higher than the TF value analyzed based on Keywords.

Table 4 Analysis of Number of Frequency for Each Research Location

\begin{tabular}{|l|c|c|}
\hline \multicolumn{1}{|c|}{ Site } & $\begin{array}{c}\text { Term Frequency Analysis of All } \\
\text { Reviews }\end{array}$ & $\begin{array}{c}\text { Term Frequency Reviews Analysis } \\
\text { related 'Walk(case)' }\end{array}$ \\
\hline Pearl & 234 & 139 \\
\hline Katara & 219 & 35 \\
\hline Souq Waqif & 211 & 197 \\
\hline Museum of Islamic Art & 420 & 83 \\
\hline Qatar Museum & 223 & 223 \\
\hline Metro & 145 & 140 \\
\hline
\end{tabular}

As shown in Table 5, top 10 frequent words for each place are derived from datasets to identify keywords that become issues at the location. The perception of walk and recognition/characteristics of public transportation at site is analyzed in detail, through the correlation of keywords by N-GRAM. The text mining related to 'Walk' in each place was completed after refining through text mining for the study places. When comparing the top 10 extracted keywords with frequency presented in Table 5, we found the general characteristics. For each region, we observed that there are many related words about walk for the outdoor space, such as Pearl, Souq Waqif, and MIA.

For the NMQ, TF results for the architecture itself is high. In the case of Pearl, MIA, and NMQ, it was difficult to find words related to Metro, due to no Metro close to or not yet being actively used. TF of Pearl presents the characteristics of Pearl regions such as 'walk', 'beautiful', 'marina', 'chill out', and 'restaurant', which are place-like features in relation to walk, was derived. In Katara's case, key words related to Metro are easily found such as 'metro station', 'shuttle bus', 'accessible', and 'red line running around Metro' were found. The symbol of Katara, Blue Mosque, is also found.

For Souk Waqif, text mining presents unique features such as 'walk', 'tour', 'automatic', 'accessible to Metro', 'walk way', and 'side walk'. When looking at keywords in MIA, as well as 'evening' and 'night' that characterize time, words about MIA's external landscape, such as 'walk', 'park', and 'corniche', were easily encountered. There was also a lot of frequency of words indicating Souq Waqif, but there was no direct metro-related word. In the N-Gram for IMA, it illustrates 'Islamic art', 'amazing architect', and ' 2 or 3 hours tour in the Museum', 'Coffee shop' and 'gift shop', representing its placeability. NMQ Keywords indicate Museum itself and 'architecture', 'desert rose', and 'modern', but no keywords related to walk or metro appeared. N-Gram of the NMQ shows these features more pronounced; 'French Architect Jean Nouvel', 'amaze and excellent Museum'. It is expected that many people are lack of experience or understanding of Metro exit since the exit is still under construction. 
Table 5. Term Frequency of Keywords for Each Research Location

\begin{tabular}{|c|c|c|c|c|c|c|c|c|c|c|c|}
\hline Place & Keyword & TF & Percent & Place & Keyword & $\mathrm{TF}$ & Percent & Place & Keyword & TF & Percent \\
\hline \multirow{10}{*}{ Pearl } & walk & 71 & $22.90 \%$ & \multirow{10}{*}{ Katara } & metro & 12 & $13.33 \%$ & \multirow{10}{*}{$\begin{array}{c}\text { Souq } \\
\text { Waqif }\end{array}$} & walk & 129 & $26.00 \%$ \\
\hline & nice & 12 & $3.87 \%$ & & Shuttle bus & 8 & $9.66 \%$ & & nice & 20 & $4.42 \%$ \\
\hline & area & 9 & $2.90 \%$ & & station & 6 & $6.66 \%$ & & metro & 13 & $2.62 \%$ \\
\hline & place & 8 & $2.58 \%$ & & red line & 6 & $6.66 \%$ & & souqwaqif & 12 & $2.41 \%$ \\
\hline & shop & 8 & $2.58 \%$ & & bus & 5 & $5.55 \%$ & & place & 9 & $1.81 \%$ \\
\hline & beautiful & 6 & $1.93 \%$ & & clean & 3 & $3.33 \%$ & & enjoy & 9 & $1.81 \%$ \\
\hline & enjoy & 6 & $1.93 \%$ & & ride & 3 & $3.33 \%$ & & market & 8 & $1.61 \%$ \\
\hline & great & 5 & $1.61 \%$ & & walk & 3 & $3.33 \%$ & & doha & 7 & $1.41 \%$ \\
\hline & evening & 5 & $1.61 \%$ & & accessible & 3 & $3.33 \%$ & & evening & 5 & $1.01 \%$ \\
\hline & restaurant & 4 & $1.29 \%$ & & taxi & 3 & $3.33 \%$ & & narrow & 5 & $1.01 \%$ \\
\hline \multirow{10}{*}{$\begin{array}{c}\text { Museum } \\
\text { of Islamic } \\
\text { Art }\end{array}$} & walk & 53 & $29.94 \%$ & \multirow{10}{*}{$\begin{array}{l}\text { National } \\
\text { Museum } \\
\text { of Qatar }\end{array}$} & museum & 50 & $8.98 \%$ & \multirow{10}{*}{ Metro } & metro & 18 & $7.00 \%$ \\
\hline & park & 8 & $4.51 \%$ & & architecture & 32 & $5.93 \%$ & & clean & 10 & $3.89 \%$ \\
\hline & distance & 7 & $3.95 \%$ & & amaze & 30 & $5.38 \%$ & & doha & 7 & $2.72 \%$ \\
\hline & souq & 7 & $3.95 \%$ & & qatar & 21 & $3.77 \%$ & & new & 7 & $2.72 \%$ \\
\hline & nice & 5 & $2.82 \%$ & & build & 14 & $2.51 \%$ & & easy & 7 & $2.72 \%$ \\
\hline & gallery & 4 & $2.26 \%$ & & modern & 13 & $2.33 \%$ & & efficient & 6 & $2.33 \%$ \\
\hline & view & 3 & $1.69 \%$ & & interest & 13 & $2.33 \%$ & & travel & 5 & $1.94 \%$ \\
\hline & walkway & 3 & $1.69 \%$ & & stunning & 10 & $1.79 \%$ & & excellent & 5 & $1.95 \%$ \\
\hline & easy & 3 & $1.69 \%$ & & great & 10 & $1.79 \%$ & & train & 5 & $1.95 \%$ \\
\hline & corniche & 3 & $1.69 \%$ & & impress & 9 & $1.61 \%$ & & convenien & 3 & $1.17 \%$ \\
\hline
\end{tabular}

Keyword's TF alone has limitations in recognizing the tourist's opinion and idea for walk in each region, so $\mathrm{N}$-Gram as shown in Table 6 is adopted to supplement the results. In N-Gram, the greater the correlation of words, the greater the size and thickness of the arrow. It allows us to understand the flow of the reviewer's thinking by following the arrow.

In Peal, a network of words that connect like 'afternoons', 'great', 'beautiful' and 'many people have walk' are presented. In the case of Souq Waqif, it is witnessed the link from 'walk' to 'market', 'accessible to Metro' to 'market', and 'Accessible to metro' and 'cheap clean metro'. Though "Metro" was not in the major list in TF, its characteristics was witnessed in the walk environment of Souq Waqif with N-Gram. In the case of MIA and NMQ, museum itself acts as like central to the connection of other words than ' walk'. From N-Gram of MIA shows the link of 'time required to view', 'walk to souk', and information of 'great walk, easy walk, nice park'. For NMQ, the building concept of 'desert rose', 'architect', and 'exhibition of Museum' are seen at the top. In consideration of newly introduced public mass transportation, Doha Metro, the analysis of the word "Metro" itself is conducted and it presents a random analysis of connecting to each expression, not as a centered on a single word. Users' main opinions towards the Doha Metro are mostly "excellent" and "very good", and show their interests in "day pass", "standard class", and "family section". This is a positive element that can be a unique experience related to the Qatar culture. 
Baek, J.; Khamidi, M.F.

A Study on the Perception of Walkability in Tourist Attraction Places in Qatar using Text Mining Techniques

Table 6. Word Cloud Graph and N- GRAM Network Graph based on TripAdvisor CGC Data

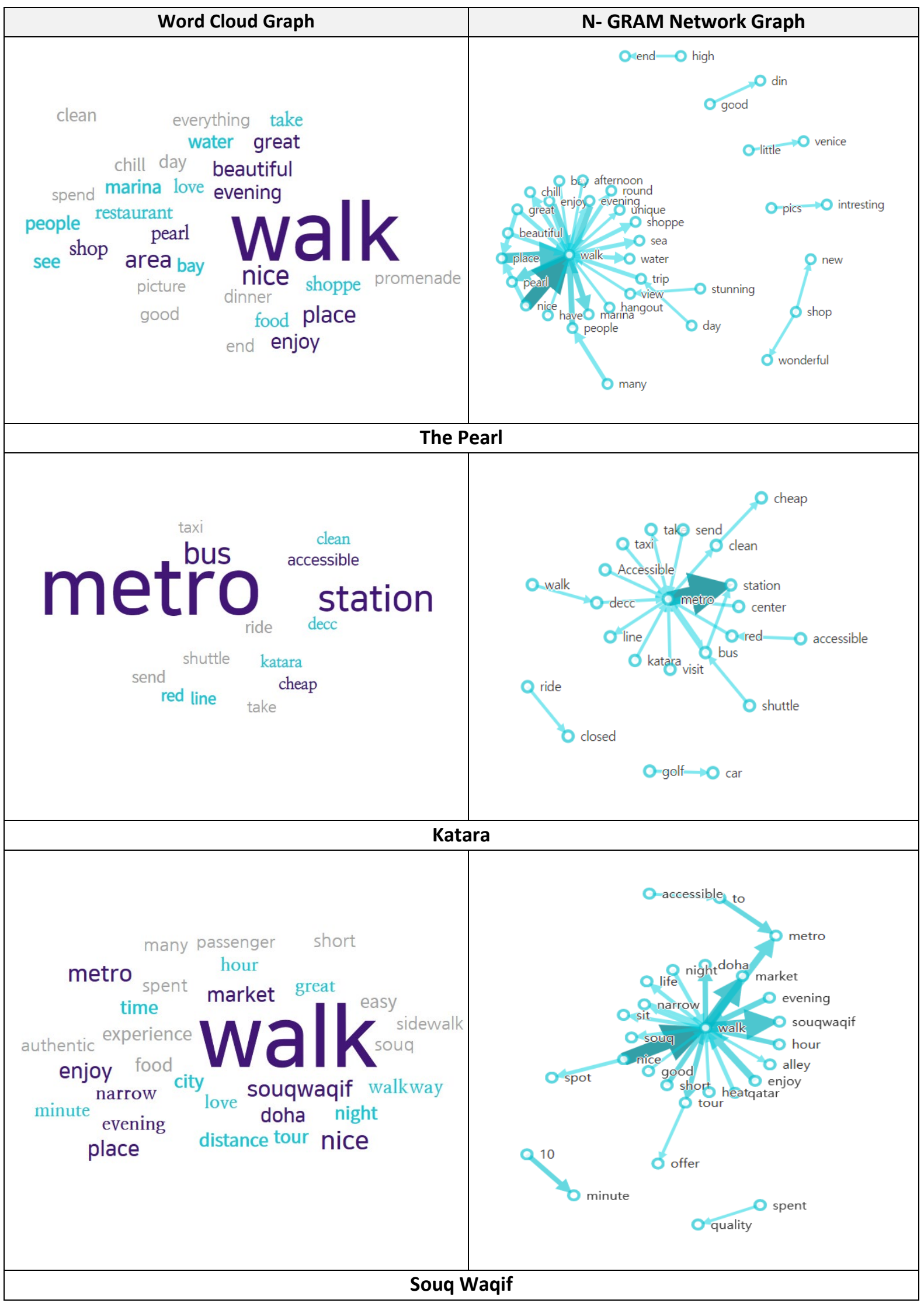




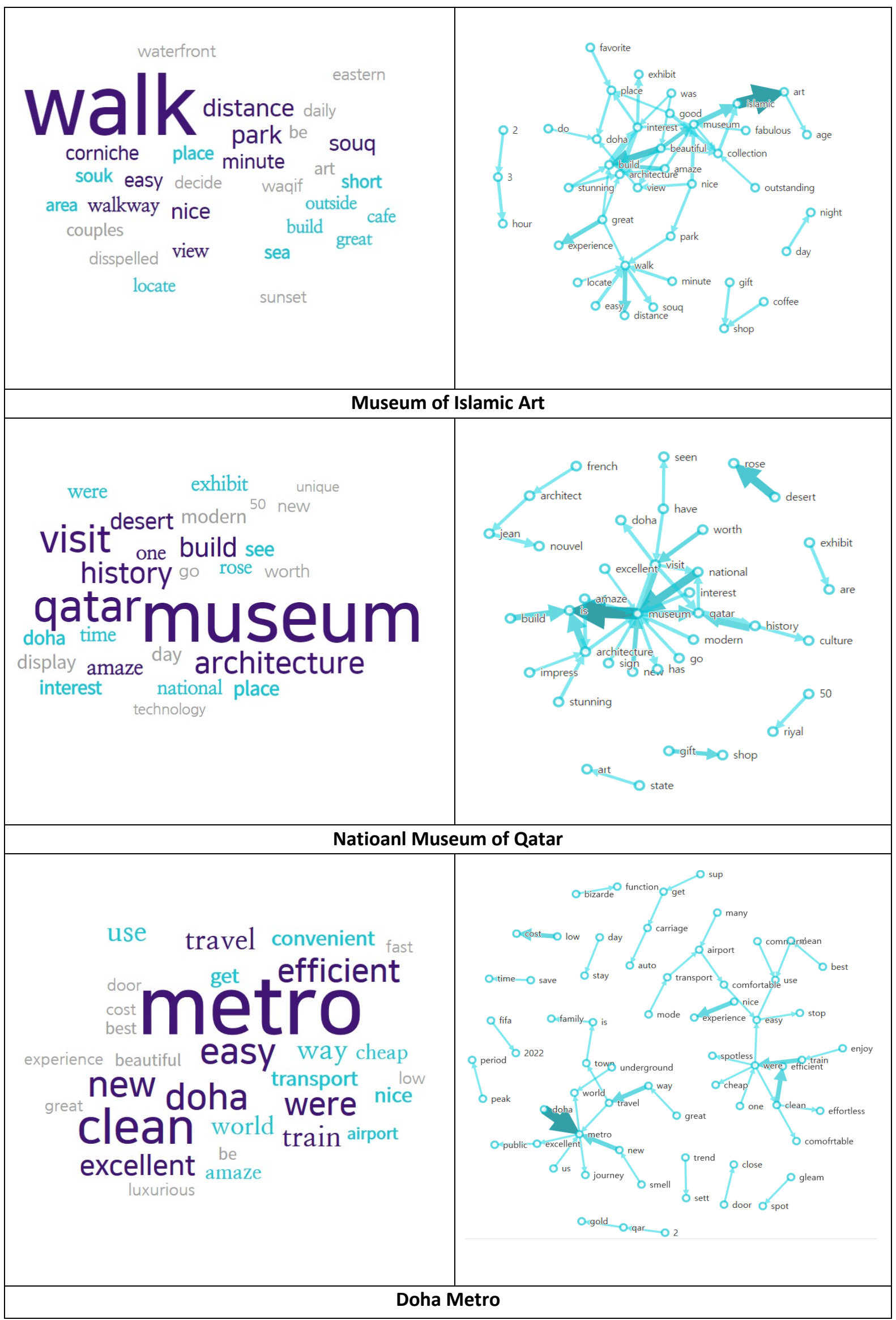




\section{Conclusion and Way Forward}

This study seeks to find out the interrelationship/effectiveness between the newly opened Doha Metro and attractive tourist places in Doha, using text mining techniques, mapping and photographs. The research method investigates the distances from each metro to the tour place based on the proper distance of $1 / 4$ miles (approximate 400 meter) described in the sustainable urban design. Based on text mining analysis extracted from the review of TripAdvisor related to relevant keywords - 'walk'; firstly is the highest frequency of words that well reflect the characteristics of each place can be determined especially for research locations like The Pearl, Souq Waqif and Museum of Islamic Arts.

Second in the frequency of data analysis, where keyword 'Metro' has also been applied to the selected sites. However, there is weak relationship between the research locations and Metro. It means that, there is not much information appeared neither about Doha Metro in research location datasets, nor research location names are in Doha Metro dataset. It is expected that the rate of Metro use is still low compared to the city's population and this will take some time for Doha Metro to be used as main mode of transportation among the tourists.

This paper, moreover, explores and investigates the possibility of utilizing/analyzing CGC data from social media to extract user's opinions about a selected place using text mining analysis. The outcome of this study will be able to propose some guidelines to enhance the walking environment for tourists within the challenging weather condition like hot and arid climate of Qatar.

\section{References}

Al-Harami, A. and Furlan, R. (2020) 'Qatar National Museum-Transit oriented development: The masterplan for the urban regeneration of a green TOD', Journal of Urban Management, 9(1), p115-136.

Kim, S.H, Lee, Y.J., Shin, J.Y., and Park, K.Y. (2019) 'Text Mining for Economic Analysis', BOK Economic Research, 2019-18.

Dubois, G., Peeters, P., Ceron, J.P., and Gossling, S. (2011) 'The future tourism mobility of the world population: Emission growth versus climate policy', Transportation Research Part A: Policy and Practice, 45(10), p1031-1042.

Forsyth, A. (2015) 'What is a walkable place? The walkability debate in urban design', Urban Design International, 20(4), p274-292.

Forsyth, A. and Southworth, M. (2008) 'Cities afoot-Pedestrians, walkability and urban design', Journal of Urban Design, 13(1), p1-3.

Gursoy, D., Del Chiappa, G. and Zhang, Y. (2017) 'Preferences regarding external information sources: a conjoint analysis of visitors to Sardinia, Italy', Journal of Travel \& Tourism Marketing, 34(6), p806-820.

Hall, C.M., Le-Klahn, D., and Ram, Y. (2017) Tourism, Public Transport and Sustainable Mobility, Channel View, Bristol.

IBM (2015) Big Data and Analytics [Online]. Availabe at: http://www-

01.ibm.com/software/data/bigdata/whatis-big-data.htmlJovicic 2019/(Accessed: 20 July 2020)

Jung, G.H. (2010) A Study of Foresight Method Based on Textmining and Complexity Network Analysis, KISTEP

Kelly, C.E., Tight, M.R., Hodgson, F.C., and Page, M.W. (2011) 'A comparison of three methods for assessing the walkability of the pedestrian environment', Journal of Transport Geography' 19(6), p1500-1508. 
Larsen, J., El-Geneidy, A., and Yasmin, F. (2010) 'Beyond the quarter mile: Re-examining travel distances by active transportation', Canadian Journal of Urban Research: Canadian Planning and Policy, 19(1), p70-88.

Le-Klahn, D., Gerike, R., and Hall, C.M. (2014) 'Visitor users vs. non-users of public transport: The case of Munich, Germany', Journal of Destination Marketing \& Management [Online]. Available at: doi:10. 1016/j.jdmm.2013.12.005(Accessed: 2 July 2020)

Le-Klähn, D. and Hall, C.M. (2015) 'Tourist use of public transport at destinations-a review', Current Issues in Tourism, 18:8, p785-803.

Litvin, S.W. and Dowling, K.M. (2016) 'TripAdvisor and hotel consumer brand loyalty' Current Issues in Tourism [Online]. Available at: http://dx.doi.org/10.1080/13683500.2016.1265488(Accessed: 2 July 2020)

Liu, B. (2010) Sediment analysis and sujectivity, Handbook of Natural Language Processing, 2nd, Chapman and Hall, CRC

Lo, R.H. (2009) 'Walkability: what is it?', Journal of Urbanism: International Research on Placemaking and Urban Sustainability, 2(2), p145-166.

Malhado, A.C.M. and Rothfuss, R. (2013) 'Transporting 2014 FIFA World Cup to sustainability: Exploring residents' and tourists' attitudes and behaviours', Journal of Policy Research in Tourism, 5(3), p252-269.

Moudon, A.V. and Lee, C. (2003) 'Walking and Bicycling: An Evaluation of Environmental Audit Instruments', American Journal of Health Promotion, 18 (1), p21-37.

Oh, D. (2015) 'Exploring Feasibility of Using Sentiment Analysis of Visitor Reviews as User Survey of Public Open Space: Based on Trip Advisor's Visitor Reviews on Gwanghwamun Square', Urban Design Institute of Korea, 16(4), p17-28.

Ram, Y. and Hall, C.M. (2018) Walkable places for visitors: Assessing and designing for walkability, The Routledge international handbook of walking studies, Routledge, Abingdon.

Samarasekara, G.N., Fukahori, K., and Kubota, Y. (2011) 'Environmental correlates that provide walkability cues for tourists: an analysis based on walking decision narrations', Environment and Behavior, 43(4), p501-524

Scott, D., Gossling, S., and Hall, C.M. (2012) 'International tourism and climate change', Wiley Interdisciplinary Reviews, 3(3), p213-232.

Speck, J. (2013) Walkable City: How Downtown Can Save America, One Step at a Time. New York: Farrar, Straus and Giroux.

Talen, E. (2002). 'Pedestrian access as a measure of urban quality', Planning Practice \& Research, 17(3), p257-278.

Talen, E. and Koschinsky, J. (2013) 'The walkable neighborhood: A literature review', International Journal of Sustainable Land Use and Urban Planning, 1(1), p42-63.

Thompson, K. (2004) 'Tourists' use of public transportation information: What they need and what they get', Paper from the European Transport Conference 04/10/2004-06/10/2004, Strasbourg, France.

Thompson, K. and Schofield, P. (2007) 'An investigation of the relationship between public transport performance and destination satisfaction', Journal of Transport Geography, 15(2), p136-144.

Timothy, D.J. and Boyd, S.W. (2015). Tourism and trails: Cultural, ecological and management issues. Bristol: Channel View.

TripAdvisor (2020). 'About TripAdvisor' [Online]. Available at: https://www.tripadvisor.com(Accessed: 9 July 2020)

Won, J.Y. and Kim, D.G. (2014) 'Deduction of social risk issues using text mining', Crisisonomy, 10(7), p3352 
Baek, J.; Khamidi, M.F.

A Study on the Perception of Walkability in Tourist Attraction Places in Qatar using Text Mining Techniques

Xiao, S., Jia, L., and Jiang, L. (2012) 'Forest recreation opportunity spectrum in the suburban mountainous region of Beijing'. Journal of Urban Planning and Development, 138(4), p335-341. 